\title{
Prediction of Job Satisfaction \& Burnout on Criminal Judges Based on Psycap
}

\author{
Sedigheh Samani ${ }^{1 *}$ and Seyyed Abolghasem Mehri Nejad ${ }^{2}$ \\ ${ }^{1}$ Islamic Azad University, Iran \\ ${ }^{2}$ Alzahra University, Iran
}

Submission: May 01, 2018; Published: September 27, 2018

*Corresponding author: Sedigheh Samani, Master of Clinical Psychology, Islamic Azad University, Science and Research Branch, Semnan, Iran; Tel: +989121596290; Email: mary.saman49@Gmail.com

\begin{abstract}
As a widely regarded positive psychology concept, psychological capital results in flexibility. Significance of the psychological capital is increased for those with difficult jobs, especially those dealing with customers engaged with serious psychosocial disorders. The present research is aimed at predicting job satisfaction and job burnout among Iranian criminal judges based on psychological capital. The present study was performed using a survey-correlational method. As a statistical sample, a total of 210 criminal judges from all Iranian provinces were selected via convenient sampling. Questionnaires collected from 23 judges were omitted from data analysis stage due to incompleteness. The questionnaires developed by Luthans, Spector, and Maslach were utilized to evaluate psychological capital, job satisfaction, and job burnout, respectively.

Considering the obtained data, all the psychological capital components were found to exhibit significant positive relationships with the job satisfaction among criminal judges $(\mathrm{p}<0.003)$. However, results of multivariate regression analysis for predicting job satisfaction showed that hope and self-efficacy were the most important factors when it came to the prediction of job satisfaction among criminal judges $(\mathrm{p}<0.001)$. In addition, hope alone was the most important inverse predictive factor for job burnout among criminal judges ( $<0.001)$. It seems that paying attention to and enhancement of psychological capital among criminal judges serve as effective solutions for lowering their job burnout while improving their job satisfaction considering the judgment career-associated pressures and exhaustion. An increase in hope was found to be more effective than the other two components.
\end{abstract}

Keywords: Resilience; Optimism; Self-efficacy; Hope; Job satisfaction; Job burnout

\section{Introduction}

Judgment is a very difficult job, with its difficulty well demonstrated when it comes to judgment in criminal court. A criminal judge requires characteristics to be able to manage his/her stress and exhibit adequate efficiency regardless of all the ups and downs he/she may deal with from the time when the crime is committed to the final passage of sentence by the court. Among very important such characteristics, one may refer to psychological characteristics. Among other psychological characteristics, psychological capital refers to a set of characters and has been well regarded during the past decades.

According to Luthans, psychological capital is composed of four dimensions, namely resilience, hope, self-efficacy, and optimism [1]. Each of these four dimensions describes positive psychological capacity, has validated measurement scale based on relevant theories and research works [2], is state-dependent, capable of growth, and significantly associated with functional consequences [3], contributes to the individual's effort to change in stressful situations and prepare him/her for stepping in the action phase [4]. Creed et al. [5] urged that, these four resources synergize one another in an interconnected system and serve as a firm shield against pressure.

As a dimension of psychological capital, resilience refers to the ability to recover original or even reach a higher level of balance, which, in difficult situations, helps the individual behave more adaptively. Therefore, it should be emphasized that, a human's principal need in the $21^{\text {st }}$ century is to train "resilience". A set of skills are required before resilience can be trained, and three components affect that, namely commitment, control, and challenging [6].

Regarding the resilience, Connor and Davidson stipulate that, resilience is not only the stability against damages or threatening obstacles, but also active and constructive participation in the surrounding environment [7]. Given that any stressful event may impose an even more sever effect due to its cumulative nature, the resilience has been increasingly regarded in discussions on personal capability and stress, finding deeper applications 
in latest findings [8]. Researchers have classified resilience at three levels, namely personal resilience, family resilience, and organizational resilience [9]. In personal resilience, at shocking moments, the individual effectively exhibits a positive and adaptive behavior. Therefore, the resilience occurs upon facing by a resident thread or unexpected and shocking event [10].

Hope is a measure of a person's ability to reach his/he goal and imagine a path toward the goal. Optimism refers to positive causal evidences on which basis the individual can describe positive and negative events and move towards positive results [11]. Self-efficacy is the confidence and belief in one's self power and capability for performing a task [12]. When a person believes in his/her self-efficacy, his/her decision on conducting the work affects the required level of effort and hard-working for accomplishing the responsibility [13]. Job burnout refers to negative alterations in attitude, spirit, and behavior against job-related psychological pressures. Maslach and Jackson presented the most common definition for job burnout: job burnout is a psychological indicator of emotional exhaustion, depersonalization and reduced personal accomplishment [14].

Emotional exhaustion resembles psychological pressure, inducing into the person a sense of being subjected to pressurization and degradation of emotional resources [15]. Depersonalization is a negative and callous response to those who usually receive a service from the person [16]. Reduced sense of accomplishment and success is a negative appraisal of self in performing the task [17]. According to Mazlak, job burnout has acted as a cause behind quitting job, absence at workplace, and low spirit as well as such disorders as physical exhaustion, insomnia, family problems and marital issues [18]. This disorder is known to develop with time, and although it is not a psychological disorder in nature, it may develop into a psychological disability [19].

Paniz and Arenson refer to job burnout as exhaustion and physical-psychological degradation syndrome, which develops because of increased level of negative job attitudes and loss of interest in colleagues [20]. Various factors have found to contribute to job burnout, including environmental, personal, and organizational factors. The organizational factors include management style, stringent working regulations, lack of job security, and inadequate opportunities for career promotion [21]. Ebrat, Hugan and Jiang defined job burnout as a negative response which develops by workplace [22]. Some researchers suggested that, excessive personal innovation in the carrier may also end up with job burnout [23].

One of the factors affecting productivity of work force is job satisfaction [24]. High level of job satisfaction reflects favourable organizational atmosphere [25]. According to Hawkman and Oldham, responsibility, outcome, knowledge of actual results of work-related activities, and meaningfulness of the job are some of the factors affecting job satisfaction [26]. Job satisfaction further depends on the one's expectations of his/her job [27]. Job satisfaction is a key factor in achieving success in job and enhances efficacy and self-satisfaction [28]. Individuals who are satisfied with their job are more likely to proceed with their job [28].

Personnel with higher levels of job satisfaction exhibit better physical health and mental abilities [29]. Measured based on the degree of adaptability to work conditions and psychosocial characteristics, job satisfaction is an indication of career performance of individuals [30]. In addition, job satisfaction is, indeed, one's emotional attitude toward his/her job [31]. According to Spector (1997) [32], four groups of factors may affect job satisfaction: organizational factors, environmental factors, nature of the job, and personal factors [33].

Investigations show that, "immigration judges", who are dealing with more cases compared to other judges and are to judge against painful and bitter stories of people's life, are usually faced by higher risks of stress and suffer from more severe symptoms of secondary traumatic stress than that faced by caregivers, prisoners, and medics working at busy hospitals [34]. In a research performed on causes of burnout among Chinese judges and attorneys, requests for help and excessive effort and job commitment were recognized as the key factors contributing to job burnout. Furthermore, low social support at workplace and direct communication with clients further contributed to burnout of the judges [35]. However, in this research, the judges who enjoyed greater deals of psychological capital were less engaged with job burnout.

Another research work on Hong Kong police department investigated the role of psychological capital and positive emotions in job satisfaction and job quitting. In this study, the relationships among positive feelings, job satisfaction and stress indicators were studied among a total of 311 police officers. The results indicated that, psychological capital and positive feelings are associated directly, while positive feelings exhibit an inverse association with stress [36]. Given the above research works, in the present research, predictive roles of components of psychological capital in job burnout among criminal judges are investigated.

\section{Materials and Methods}

The present research was performed following a surveycorrelational methodology. In this study, prediction of job burnout and job satisfaction based on psychological capital was considered among criminal judges from all provinces of Iran. Statistical population of the research was composed of all those criminal judges in the country who were ready to participate in the research. A total of 210 criminal judges were sampled, but the data acquired from 23 judges was discarded from the analysis due to incompleteness. The sample was selected via convenient sampling method. 


\section{Psychology and Behavioral Science International Journal}

\section{Research Instruments}

\section{Psychological capital questionnaire}

Designed by Luthans (2007) for professional environments, this questionnaire has four dimensions, namely resilience, hope, self-efficacy, and optimism. Reliability and validity of each dimension have been frequently verified with a Cronbach's alpha of 0.85 [37]. In Iran, Foroohar et al. [38] obtained a Cronbach's alpha of 0.87, while Nosrat-Abadi et al. [39] and Bahadori Khosroshahi (2012) ended up with a Cronbach's alpha of 0.85 . Formal and content validities of the questionnaire have been also verified [39]. In the present research, a Cronbach's alpha of 0.80 was obtained.

\section{Job satisfaction questionnaire}

Spector (1985) designed this questionnaire and obtained a Cronbach's alpha of 0.80 . In Iran, investigating reliability and validity of this questionnaire, Javadian et al. [40] reported a Cronbach's alpha of 0.88 . In the present research, Cronbach's alpha was found to be 0.91 .

\section{Job burnout questionnaire}

Developed by Maslach and Jackson (1981), this questionnaire contains 22 questions evaluating three dimensions, namely emotional burnout, depersonalization, and personal accomplishment, based on Likert scale. Internal stability of this questionnaire has been confirmed in several research works. In Iran, the questionnaire was first translated by Filian (1991). Internal reliability of the questionnaire, as measured by Cronbach's alpha, was found to be 0.90 and 0.79 for the sub-scales of emotional exhaustion and depersonalization, respectively [41]. To measure reliability of this questionnaire, Najafi correlated it to the job satisfaction questionnaire developed by Smith, Kendal and Haline and ended up with a correlation coefficient of 0.76 [42]. In this project, the Cronbach's alpha was found to be 0.88 .

Results

Table 1: Distribution of age and work experience of the studied male judges.

\begin{tabular}{|c|c|c|c|c|}
\hline Variable & Minimum & Maximum & Mean & $\begin{array}{c}\text { Standard } \\
\text { Deviation }\end{array}$ \\
\hline Age (years) & 28 & 66 & 45.8 & 27.22 \\
\hline $\begin{array}{c}\text { Work experience } \\
\text { (years) }\end{array}$ & 3 & 35 & 20.2 & 7.13 \\
\hline
\end{tabular}

As can be seen in Table 1, on average, the individuals participating in this research were $45.8 \pm 27.22$-year-old, with an average work experience of $20.2 \pm 7.13$ years, all of whom were men. According to the findings reported in Table 2, most of the studied judges had master's degrees. As can be observed in Table 3, all components of psychological capital (self-efficacy (0.336), hope (0.358), resilience (0.307), and optimism (0.178)) exhibited significant positive correlations to job satisfaction among judges. Among others, the hope (0.358) and optimism (0.178) exhibited the highest and lowest correlation coefficients to job satisfaction, respectively.
Table 2: Distribution of education level of the make judges studied in this research.

\begin{tabular}{|c|c|c|}
\hline Education Level & Frequency & Percentage \\
\hline Graduate & 54 & 28.9 \\
\hline Post-graduate & 103 & 55.1 \\
\hline Ph. D & 30 & 16 \\
\hline Total & 187 & 100 \\
\hline
\end{tabular}

Table 3: Spearman's rank correlation coefficient between job satisfaction and psychological capital.

\begin{tabular}{|c|c|c|c|}
\hline Variable & Component & $\begin{array}{c}\text { Correlation } \\
\text { Coefficient }\end{array}$ & Probability \\
\hline \multirow{4}{*}{$\begin{array}{c}\text { Psychological } \\
\text { capital }\end{array}$} & Self-efficacy & 0.336 & $<0.001$ \\
\cline { 2 - 4 } & Hope & 0.358 & $<0.001$ \\
\cline { 2 - 4 } & Resilience & 0.307 & $<0.001$ \\
\cline { 2 - 4 } & Optimism & 0.178 & $<0.015$ \\
\cline { 2 - 4 } & Total & 0.407 & $<0.001$ \\
\hline
\end{tabular}

According to Table 4, all components of psychological capital (self-efficacy $(-0.187)$, hope $(-0.326)$, resilience $(-0.252)$, and optimism (-0.192)) exhibited significant negative (inverse) correlation to job burnout among judges. Among others, the resilience $(-0.252)$ and optimism $(-0.192)$ exhibited the highest and lowest correlation coefficients to job burnout, respectively. To measure the relationships between job satisfaction and burnout among the criminal judges and components of psychological capital, stepwise multivariate regression was used where each of the components of psychological capital was considered as predictive variable, with the job satisfaction and burnout being considered as the variable to be predicted.

Table 4: Spearman's rank correlation coefficient between job burnout and components of psychological capital.

\begin{tabular}{|c|c|c|c|}
\hline \multirow{2}{*}{ Variable } & Component & $\begin{array}{c}\text { Correlation } \\
\text { Coefficient }\end{array}$ & p-value \\
\hline \multirow{4}{*}{$\begin{array}{c}\text { Psychological } \\
\text { capital }\end{array}$} & Self-efficacy & -0.187 & $<0.011$ \\
\cline { 2 - 4 } & Hope & -0.326 & $<0.001$ \\
\cline { 2 - 4 } & Resilience & -0.252 & $<0.001$ \\
\cline { 2 - 4 } & Optimism & -0.192 & 0.008 \\
\cline { 2 - 4 } & Total & -0.331 & $<0.001$ \\
\hline
\end{tabular}

According to Table 5, among the components of psychological capital among criminal judges, self-efficacy $(\mathrm{p}<0.001)$ and hope $(p<0.001)$ exhibit significant positive relationships to job satisfaction, while $p$-values of other variables $(p>0.05)$ indicate insignificance of the corresponding relationships, so that those were omitted from the analyses. Self-efficacy (estimated coefficient: 1.315) and hope (estimated coefficient: 0.861) exhibited direct and significant relationships with and could predict job satisfaction among criminal judges.

A comparison among estimated standardized coefficients showed that, the most significant factors for the job satisfaction among criminal judges have been the hope (0.173) and selfefficacy (0.283). Age and work experience were omitted from 


\section{Psychology and Behavioral Science International Journal}

the model because of their large $p$-values ( $p>0.05)$. According to Table 6, among the components of psychological capital among criminal judges, hope $(\mathrm{p}<0.001)$ can predict job burnout, while $\mathrm{p}$-values of other variables $(\mathrm{p}>0.05)$ indicate insignificance of their relationships, so that those were omitted from the

\begin{tabular}{|c|c|c|c|c|c|c|}
\hline Model & Variable & $\begin{array}{l}\text { Estimated } \\
\text { Coefficient }\end{array}$ & Standard Error & $\begin{array}{c}\text { Standardized } \\
\text { Coefficient }\end{array}$ & p-value & $\begin{array}{c}\text { Variance Inflation Factor } \\
\text { (VIF) }\end{array}$ \\
\hline \multirow{6}{*}{ Primary } & Self-efficacy & 0.975 & 0.399 & 0.196 & 0.015 & 1.407 \\
\hline & Hope & 0.985 & 0.464 & 0.212 & 0.35 & 2.189 \\
\hline & Resilience & 0.828 & 0.537 & 0.147 & 0.125 & 2.009 \\
\hline & Optimism & -0.524 & 0.522 & -0.085 & 0 & 1.592 \\
\hline & Age (year) & 410 & 0.431 & 0.128 & 0.343 & 3.994 \\
\hline & Work experience (year) & -0.164 & 0.481 & -0.046 & -0.342 & 3.968 \\
\hline \multirow{2}{*}{ Final } & Hope & 0.861 & 0.394 & 0.173 & 0.03 & 1.374 \\
\hline & Self-efficacy & 1.315 & 0.368 & 0.283 & $<0.001$ & 1.374 \\
\hline
\end{tabular}

Table 6: Results of fitting the linear multivariate regression model of psychological capital onto job.

\begin{tabular}{|c|c|c|c|c|c|c|}
\hline \multirow{3}{*}{ Model } & Variable & $\begin{array}{c}\text { Estimated } \\
\text { Coefficient }\end{array}$ & $\begin{array}{c}\text { Standard } \\
\text { Error }\end{array}$ & $\begin{array}{c}\text { Standardized } \\
\text { Coefficient }\end{array}$ & $\begin{array}{c}\text { p-value } \\
\text { Variance Inflation } \\
\text { Factor (VIF) }\end{array}$ \\
\hline \multirow{4}{*}{ Primary } & Self-efficacy & 0.054 & 0.41 & -0.011 & 0.896 & 1.407 \\
\cline { 2 - 8 } & Hope & -1.545 & 0.477 & -0.324 & 0.001 & 2.189 \\
\cline { 2 - 8 } & Resilience & -0.514 & 0.552 & -0.089 & 0.353 & 2.009 \\
\cline { 2 - 8 } & Optimism & 0.207 & 0.536 & 0.033 & 0.7 & 1.592 \\
\cline { 2 - 8 } & Age (year) & -1.096 & 0.443 & -0.334 & 0.014 & 3.994 \\
\hline \multirow{3}{*}{ Secondary } & Work experience (year) & 0.865 & 0.494 & 0.226 & 0.081 & 3.968 \\
\cline { 2 - 8 } & Hope & -1.737 & 0.322 & -0.372 & $<0.001$ & 1.002 \\
\hline \multirow{2}{*}{ Final } & Age (year) & -0.432 & 0.222 & -0.132 & 0.053 & 1.002 \\
\hline
\end{tabular}

Investigation of estimated standardized coefficients showed that, job burnout is associated with only hope (0.011) and resilience (0.033), via significant inverse (negative) associations. To measure job burnout, the questionnaire developed by Maslach was used with five-point Likert scales, so that an increase in Table 7: Results obtained from components of job burnout. analyses. In the secondary model, however, compared to hope, age indicated a $p$-value of $p>0.05$, and thereby omitted from the final model. In the final model, only hope indicated a significant yet inverse effect on job burnout (-1.802).

\begin{tabular}{|c|c|c|c|c|}
\hline \multirow{2}{*}{ Status/Component } & Critical & Severe & Acceptable & Desirable \\
\cline { 2 - 5 } & $3.5 \leq \mathrm{M} \leq 4.5$ & $2.5 \leq \mathrm{M} \leq 3.5$ & $1.5 \leq \mathrm{M} \leq 2.5$ & $0.5 \leq \mathrm{M} \leq 1.5$ \\
\cline { 2 - 5 } & & & \multicolumn{2}{|c|}{ Notable } \\
\hline Emotional exhaustion & & & 2.41 & \\
\hline Depersonalization & & & 1.69 & \\
\hline Personal accomplishment & & & 2.19 & \\
\hline
\end{tabular}

Investigation of dimensions of job burnout based on Table 7 shows that, even though the components of emotional exhaustion, depersonalization and personal accomplishment are apparently acceptable, but emotional exhaustion (2.41) and personal accomplishment (2.19) fall within the range of notable values while the depersonalization (1.69) is close to the desirable range, urging for long-term actions. Emotional exhaustion is the most important component in the Maslach model. Therefore, it can be stipulated that, the main factors behind emotional the points indicated increased burnout. Under favourable, acceptable, severe, and critical conditions, average score of burnouts was less than 1.5, 1.5-2.5, 2.5-3, and greater than 3.5, respectively. The critical condition urges for immediate actions and short-term to long-term measures. exhaustion are organizational and job-related issues and high levels of job-related stress [43].

According to Maslach, when a person feels that his/ her function is not leading to any success, his/her personal accomplishment decreases (i.e. perceptual success rather than actual success) [44]. In the three-component model presented by Maslach, it is assumed that emotional exhaustion occurs firstly, followed by depersonalization and finally reduced 
personal accomplishment [44]. In the present research, however, the depersonalization component was found to be desirable, indicating good inter-personal relationships among the judges studied herein.

\section{Discussion}

The present research was aimed at predicting job satisfaction and job burnout among Iranian criminal judges based on psychological capital. Accordingly, hope (0.358) and self-efficacy $(0.336)$ could positively and significantly predict job satisfaction, while hope $(-0.326)$ and resilience $(-0.252)$ could inversely and significantly predict job burnout. In the research published by Avey et al. [45], it was revealed that, optimism is directly and significantly associated with job satisfaction; that is, individuals enjoying greater deals of psychological capital tend to exhibit deeper job involvement, thereby better accomplishing their tasks. In the present research, however, no such association was observed.

In a correlational research on resilience against psychological pressures among Chinese workers, it was found that, resilience has a positive and significant relationship with job satisfaction [46]. The relationship between self-efficacy and hope agrees with the findings by Wolfc Hoy et al. (2008). Explaining this relationship, it can be stipulated that, generating moods and attitudes (Tiger, 1979) or expectations about future (Sherrer and Cover, 2002), hope can make changes into individuals. Hoping in future tends to enhance efficacy, accomplishment, and capabilities while boosting the sense of responsibility in work. In the research by Najafi and Foolad-Chang (2007), a significant yet negative association was obtained between self-efficacy, anxiety, and depression, which agrees with the results of Kim (2003), Smith et al. (2002), Barlo et al. (2002), Andler (2001), Bendura (1999), Rambo (1998), Schwarz and Fajse (1995), and Kavanag and Baro (1985).

Individuals of higher self-efficacy tend to exhibit greater deals of effort and hard-working, and such an attitude positively affects hope [47]. As of present, no research has been performed on the relationship between self-efficacy and hope among judges, however, considering the obtained data and explaining the attained findings, it can be stipulated that, the judges who enjoy larger deals of psychological capital tend to exhibit higher selfconfidence, capabilities, creativity, organizational commitment, job involvement, and personal and organizational life qualities.

Furthermore, self-efficacy and hope result in the generation of fresh and positive attitudes toward self, others, and the surrounding world. The self-efficacy-resulted belief in one's self abilities and skills contributes to higher deals of hope, so that he/she is likely to adopt all his/her skills following a positive approach while being further satisfied with his/her job. Individuals with low self-efficacy and hope are susceptible to difficult situations and events where their stress and anxiety levels go excessively high, whereas high self-efficiency largely contributes to the development of the ability to accomplish tasks at better quality by making the individual committed to the work, attenuating possible threats, and boosting adaptability.

Results of the present research indicated a significant inverse (negative) relationship between hope and job burnout; even though no research on this relationship among judges has been reported yet, but findings of the research by Akbarzadeh, PanahAli [48] on organizational commitment showed that, resilience is predictive variable for job burnout. Moreover, Amini [49] and Momeni et al. [50] investigated such a relationship among nurses. Furthermore, in their research, Edward and Herzlisnki [51] suggested that, resilient employees tend to be less engaged with job burnout. Connor and Davidson and Hernandez [52] further confirmed this finding. In a research published in 2011, Cook investigated the role of resilience in trauma.

Indeed, resilient and tough individuals tend to dominate over undesirable effects and physical and emotional exhaustion resulted from job, thereby maintaining their psychological health. Such individuals are inspired by a great sense of progress and high levels of self-confidence. The research by Newman and Young confirmed the inverse relationship between hope and job burnout. Furthermore, Ekrami, Rezaei and Bayani confirmed such association regarding educational burnout. Trying to explain this subject, it should be noted that, the approach followed to deal with job-related challenges affects job burnout, and the more positive the individual's attitude toward his/her workspace and the more he/she can keep himself/herself away from environmental stresses, the more he/she will be protected against job burnout.

\section{Conclusion}

Based on the findings of this research, it can be concluded that, direct and indirect programs for enhancing components of psychological capital, particularly hope, self-efficacy, and resilience, can enhance job satisfaction while reducing job burnout among criminal judges in Iran. Finally, increased job satisfaction and reduced job burnout contribute to enhanced efficacy of criminal judges.

\section{References}

1. Story J, Youssef CM, Luthans F, Barbuto JE, Bovaird J (2013) Contagion effect of global leaders' positive psychological capital $n$ followers: Does distance and quality of relationship matter? The International Journal of Human Resource Management 24(13): 2534-2553.

2. Avey JB, Reichard RJ, Luthans F, Mhatre KH (2011) Meta-analysis of the impact of positive psychological capital on employee attitudes, behaviors, and performance. Human Resource Development Quarterly 22(2): 127-152.

3. Luthans F, Luthans KW, Luthans BC (2004) Positive Psychological Capital: Beyond human and social capital. Business Horizons 47(1): 45-50.

4. Judge TA, Bono JE (2001) Relationship of core self-evaluations traits-self-esteem, eneralized elf-efficacy, locus of control, and emotional stability--with job satisfaction and job performance: A meta-analysis. J App Psychol 86(1): 80-92. 


\section{Psychology and Behavioral Science International Journal}

5. Erez A, Judge TA (2001) Relationship of core self-evaluations to goal setting, motivation, and performance. J Appl Psychol 86(6): 12701279.

6. Luthans F, Avey JB, Avolio BJ, Petera JL (2008) Experimental Analysis of a Web Based Training Intervention to Develop Positive psychological Capital. Academy of Management Learning \& Education 7(2): 209-221.

7. Connor KM, Davidson JR, Lee LL (2003) Spirituality, resilience, and anger in survivors of violent trauma; A community survey. J Trauma Stress 16(5) 487-494

8. Kimhi S (2016) Levels of resilience: Associations among individual, community, .and national resilience". J health psychol 21(2): 164-170.

9. Gal R (2014) Social Resilience in Times of Protracted Crises an Israeli Case Study. Armed Forces \& Society 40(3): 452-475.

10. Canetti D, Waismel-Manor I, Cohen N, Rapaport C (2014) What Does National Resilience Mean in a Democracy? Evidence from the United States and Israel. Armed Forces \& Society 40(3): 504-520.

11. Brandt T, Gomes J, Boyanova D (2011) Personality and psychological capital as European countries. Finnish. Journal of business economics 3(11): 263-289.

12. Luthans F, Youssef C, Avolio B (2007) Psychological Capital; Developing the human Competitive edge. Oxford University Press, Oxford, England.

13. Sheikholeslami Razieh, Ahmadi Sareh (2011) Pardiction of Academic coping stratigies by to self-efficacy beliefs and goal orientation in Shiraz University Students. Research in Curriculum Planning 8(4): 5-24.

14. Hallberg UE (2005) A Thesis on fire: Studies of work engagement, Type a behavior and Burnout, Department of Psychology, University of Stockholms, Sweden.

15. Aguayo R, Vargas C, la Fuente, E, Lozano LM (2011) A meta-analytic reliability generalization study of the Maslach Burnout Inventory. International Journal of Clinical and Health Psychology 11(2): 343361

16. Nahrgang JD, Morgeson FP, Hofmann DA (2011) Safety at work: A meta-analytic investigation of the link between job demands, job resources, burnout, engagement, and safety outcomes. J Appl Psychol 96(1): 71-94.

17. Alsup PJ (2011) Job Burnout: The End or a New Beginning? A Research Paper Submitted in Partial Fulfillment of the Requirements for the Master of Science Degree. Rehabilitation Administration and Services Department. Southern Illinois University Carbondale, USA, p: 16

18. Fische R, Boer D (2011) What Is More Important for National WellBeing: Money or Autonomy? A Meta-Analysis of Well-Being, Burnout, and Anxiety across 63 Societies. Journal of Personality and Socia Psychology 101(1): 164-184.

19. Maslach C, Wilmar B, Leiter MD (2001) Job burnout. Annual Review of Psychology 52: 397-422.

20. (1998) WHO Guidelines for the primary prevention of mental neurological and psychological disorders: Staff burnout. Division of Mental Health. WHO, Geneva, Switzerland, pp. 91-108.

21. Lambert E, Hogan NL, Jiang S (2010) A preliminary examination of the relationship between organizational structure and emotional burnout among correctional staff. The Howard journal of Criminal Justice 49(2): 125-146.

22. Huhtala H, Parzefall MR (2007) A review of employee well-being and innovativeness: an opportunity for a mutual benefit. Creativity and Innovation Management Journal 16(3): 299-306.

23. Tabatabaei SH, Hosseinianb S, Gharanjiki B (2011) General health, stress associated to the work and job satisfaction of Hormozgan
Cement Factory employees in Iran. Procedia-Social and Behavioral Sciences 30(3): 1897-1901.

24. Tajvar M, khodabakhsh Nejad V, Arab M (2006) Personnel's job satisfaction in tehran koodakan kids medical center. Journal of Health Administration 9(23): 25-30.

25. Hackman JR, Oldham GR (1976) Motivation through the design of work: Test of a theory. Organizational Behavior and Human Performance 16: 250-279.

26. Remus I, Timothy A Judge (2002) Understanding the dynamic relationships among personality, mood, and job satisfaction: A field experience sampling study. Organizational Behavior and Human Decision Processes 89(2): 1119-1139.

27. Dimeglio K, Padula C, Piatek C, Korber S, Barrett A, et al. (2005) Group cohesion and nurse satisfaction: examination of a team-building approach. J Nurs Adm 35(3): 110-120.

28. Moghimi H (1377) Organization management. Research Approach, Terme Publication, Tehran, Iran.

29. Saatchi, Mahmoud (1379) Work psychology. Virayesh Publication, Tehran, Iran.

30. Price JL (2001) Reflections on determinants of voluntary turnover International Journal of Manpower 22: 600-624

31. Spector PE (1997) Job satisfaction. SAGE publications, London.

32. Gharabaghi H (2000) The Survey of the Relationship between Personality Characteristics and Job Satisfaction among Iran Teraktor Sazi co. employees. Public Psychology MA Thesis, Tabriz University, Tehran, Iran.

33. Feng-Jen, Tsai-Chang-Chuan, Chan (2010) International Archives of Occupational and Environmental Health 83(2): 133-142.

34. Lustig 0, Stuart L Lustig, Niranjan Karnik, Kevin Delucchi (2009) Cite as University of California San Francisco, Department of Psychiatry. Acknowledgment: This study was funded by a grant from the University of California San Francisco Academic Senate to International Federation of Professional and Technical Engineers National Association of Immigration Judges, USA.

35. Oi Ling Siu, Francis Cheung, Steve Lui (2015) Linking Positive Emotions to Work Well-Being and Turnover Intention Among Hong Kong Police Officers: The Role of Psychological Capital. Journal of Happiness Studies (April 2015) 16: 367-380.

36. Nelson J (2010) Building a conceptual model of academic effort for traditional first-year college students: A dissertation submitted to the School of behavioral and Applied Sciences in partial fulfillment of the requirements for the degree of Doctor of Philosophy in Higher Education at the Azusa Pacific University, USA

37. Froohar, Mohammad, Hoveida Reza, Jamshidian (2011) Explaining the Relationship between the Psychological Capital and the Enterprise Entrepreneurship of the Faculty Members of the University, Faslname Farhang Moshavere va Ravan Darmani $2^{\text {nd }}$ year, 8: 83-100.

38. Bahadori khosroshahi, Jafar, Hashemi nosrat abadi, Tooraj, Babapoor kheirodin, et al. (2011) The relation between psychological cold and social capital of students of Tabriz. Majale takhasosi pazhohesh va salamat markaze tahghigh tose ejtemaii va erteghaye salamat gonabad pp: 145-153.

39. Javadian Z, Golparvar M, Balali S (2011) The relationship between psychological contract, job satisfaction and organizational commitment unethical behaviors with the role of protest opportunity to injustice. Journal of New Findings in Psychology 6(20): 7-19.

40. Badri GarGari, Rahim (1374) Psychological Syndrome of teachers Job Burn-out and Oppositional Mechanism. MA Thesis, Tarbiat Modarres University, Iran. 
41. Najafi M, Solati D SK, Foruz Bakhsh F (1379) The relationship between Job Burn-out and Mental Health among Esfahan Research and production of nuclear fuel Center Staff. The Journal of Shahre Kord Medical Science University. $2^{\text {nd }}$ Term: 2: 34-41.

42. Elit L, Trim K (2004) Job satisfaction, stress and burnout among Canadian gynecologic oncologists. Journal Gynecologic oncologists 94(1): 134-139.

43. Maslach C, Leiter MP (2005) Reversing burnout: How to rekindle your passion for your work. Standford social innovation review, Graduate school of business.

44. Avey JB, Wernsing TS, Luthans F (2008) Can positive employees help positive organizational change? Impact of psychological capital and emotions on relevant attitudes and behaviors. Journal of Applied Behavioral Science 44(1): 48-70.

45. Siu OL, Hui CH, Phillips DR, Lin L, Wong TW, et al. (2009) A study of resiliency among Chinese health care workers: capacity to copy with workplace stress. J Res Pers 5(43): 770-776.

46. Stansberry Beard, Hoy K, Woolfolk Hoy WKA (2009) Academic Optimism of Individual Teachers: Confirming a New Construct. The Ohio State University 26(5): 1136-1144.

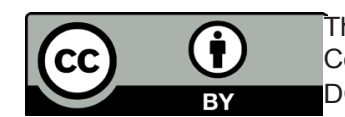

This work is licensed under Creative Commons Attribution 4.0 License DOI: 10.19080/PBSIJ.2018.09.555774
47. Akbarzadeh, Davoud, Akbarzadeh, Hasan, Panahali, et al. (2014) The relationship between organizational commitment, resilience and mental health with job burnout among employees of Firefighting organization. Quarterly of relief and rescue 6(3): 57-70.

48. Amini, Fahimeh (2013) The relationship between resilience and job burnout among nurses. Journal of research development in nursing and midwifery 2(10): 94-102.

49. Momeni, Khodamorad, Akbari, Mostafa, Atashzadeh Shourideh, et al. (2009) The relationship between resilience and job burnout among nurses. Quarterly of Teb va Tazkiyeh 74: 37-47.

50. Edward KL, Hercelinsky JG (2007) Burnout in the caring nurse: learning resilient behaviors. Br J Nurs (16): 240-246.

51. Menezes L, Fernández C, Hernández RC, Contador C (2006) Resilience and the burnout engagement model in formal caregiver of the elderly. Psicothema 18(4): 791-796.

52. Newman R (2003) Providing direction on the road to resilience. Behavioral health management 13(4): 42-43.

\section{Your next submission with Juniper Publishers will reach you the below assets}

- Quality Editorial service

- Swift Peer Review

- Reprints availability

- E-prints Service

- Manuscript Podcast for convenient understanding

- Global attainment for your research

- Manuscript accessibility in different formats

( Pdf, E-pub, Full Text, Audio)

- Unceasing customer service

Track the below URL for one-step submission https://juniperpublishers.com/online-submission.php 